\title{
ADUBAÇÃO DO PIMENTÃO (Capsicum annuum) COM AMANIPUEIRA E SEUS EFEITOS: UMA REVISÃO
}

\author{
Diana Patrícia dos Santos Ferreira ${ }^{1}$ \\ Islane Cristina Martins ${ }^{2}$
}

RESUMO: Introdução: A manipueira é um resíduo extremamente prejudicial ao meio ambiente quando descartado de forma inadequada, porém, sua utilização como o biofertilizante na agricultura torna-se possível porque possui quantidades consideráveis de macro e micronutrientes. Objetivo: O objetivo do presente estudo foi realizar uma revisão integrativa da literatura a fim de compreender a adubação do pimentão (Capsicum annuum) com a manipueira e seus efeitos. Material e Métodos: Foi feita uma busca das referências nas bases Periódicos CAPES, Google Scholar em janeiro de 2021. A busca permitiu identificação de três artigos que se adequaram aos critérios estabelecidos. Resultados: A partir da análise dos dados foi possível verificar que $67 \%$ dos artigos fizeram menção de que foi comprovado que adição de manipueira como adubo na plantação de pimentão tiveram um resultado positivo no desenvolvimento do fruto e $33 \%$ dos artigos fizeram menção que embora a manipueira apresenta vantagens dentro da temática agrícola, requer uma abordagem mais cautelosa, visto que a pesquisa e a legislação ainda são incipientes, tanto no Brasil, quanto em outros locais do mundo. Conclusão: Os efeitos da adubação do pimentão (Capsicum annuum) com a manipueira promoveu o melhor resultado para comprimento e diâmetro de fruto na dose de $20 \mathrm{~mL}$. Doses superiores a $20 \mathrm{~mL}$ reduziram o número, comprimento e diâmetro de frutos de pimentão.

Palavras-chave: Adubação. Manipueira. Pimentão.

ABSTRACT: Introduction: Manipueira is an extremely harmful waste to the environment when improperly discarded, however, its use as a biofertilizer in agriculture is possible because it has considerable amounts of macro and micronutrients. Objective: The aim of this study was to carry out an integrative literature review in order to understand the fertilization of sweet pepper (Capsicum annuum) with manipueira and its effects. Materials and Methods: A search of the references was carried out in the CAPES Periodicals, Google Scholar databases in January 2021. The search allowed the identification of three articles that met the established criteria. Results: From the data analy sis it was possible to verify that $67 \%$ of the articles mentioned that it was proven that the addition of manipueira as fertilizer in the pepper planting had a positive result in the development of the fruit and 33\% of the articles mentioned that although the Manipueira presents advantages within the agricultural theme, requires a more cautious approach, since research and legislation are still incipient, both in Brazil and in other parts of the world. Conclusion: The effects of fertilization of sweet pepper (Capsicum annuum) with

\footnotetext{
I Especialista em Gestão de Segurança de Alimentos - SENAC.

${ }^{2}$ Doutora em Neurociências -UFPE. E-mail: islanematinsıgmail.com
} 
cassava tree promoted the best result for length and diameter of fruit at a dose of $20 \mathrm{~mL}$. Doses above $20 \mathrm{~mL}$ reduced the number, length and diameter of sweet pepper fruits.

Keywords: Fertilization. Manipueira. Bell Pepper.

\section{INTRODUÇÃO}

O pimentão (Capsicum annuum) está entre as principais hortaliças cultivadas no Brasil, sendo um alimento com alto teor de valor nutricional, bem como, fonte de várias vitaminas, como A, C e E, característica medicinal devido ao alto teor de propriedades antioxidantes (RAMOS et al., 2017).

Um exemplo disso é que o pimentão é uma das dez hortaliças de maior importância econômica no mercado brasileiro (LIMA e VALENTE, 2017). Por isso, se faz necessário avaliar alternativas quanto a adubação orgânica visando redução de custos e a preservação do meio ambiente.

Porém, os solos brasileiros apresentam, em geral, baixa fertilidade e faz-se uso de adubação orgânica e mineral, para torná-los compatíveis com as exigências da cultura (LIMA e VALENTE, 2017).

Nesse sentido, existem alguns adubos importantes para esse tipo de hortaliça, como por exemplo a manipueira, conhecida também como tucupi é um resíduo gerado no processamento da mandioca, apresenta aspecto leitoso, de cor amarelo-claro oriunda das raízes da mandioca, decorrente da prensagem depois de lavada e triturada (LIMA e VALENTE, 2017).

Além disso, a manipueira é rica em potássio, nitrogênio, magnésio, fósforo, cálcio, e enxofre, além de ferro e micronutrientes. Contudo, ela apresenta um alto teor de matéria orgânica, um glicosídio chamado linamarina, que é facilmente hidrolisado a cianeto, composto altamente tóxico ao metabolismo (LIMA e VALENTE, 2017). Assim, caso seja lançada diretamente em cursos d'água, onde comumente são despejados, os resíduos líquidos industriais, a manipueira pode representar grave problema para o meio ambiente (LIMA e VALENTE, 2017).

Logo, representa uma atividade com significativo impacto ambiental negativo pela geração e produção de resíduos inorgânicos (RAMOS et al., 2017). 
Isto é, além do aspecto agressivo ao ambiente, deve ser considerado também que o despejo indevido dos subprodutos da mandioca constitui em desperdício de rendimento para o produtor (LIMA e VALENTE, 2017).

Além disso, quando consideradas as quantidades geradas e a sua composição química, devido à presença de macronutrientes e micronutrientes, pode ser aproveitada como fertilizante na agricultura, evitando impactos indesejáveis (LIMA e VALENTE, 2017).

Contudo, o reaproveitamento de águas residuárias como a manipueira está sendo estudado como fonte de manutenção da fertilidade do solo e redução do uso de água de qualidade superior (RAMOS et al., 2017).

E, segundo Bertoncini (2014), este reaproveitamento de resíduos na agricultura tornou-se uma prática viável para trazer benefícios ambientais variados pel exploração de matéria orgânica.

Além disso, ela vem sendo apontada para o uso eficiente desse efluente com potencial para produção agrícola para preservar a água de boa qualidade que pode ser utilizada para outros fins mais nobres, como o uso humano e animal (RAMOS et al., 2017). Portanto, a manipueira pode aumentar a produtividade e a qualidade dos produtos colhidos, reduzindo a poluição ambiental e a produção, custos e melhoria das características químicas, físicas e biológicas do solo (MATOS, 2007).

Porém, o paradigma agrícola está entre alcançar simultaneamente a produtividade agrícola e a sustentabilidade ambiental, logo, é imprescindível a busca por sistemas alternativos de produção que minimizem esses danos (RAMOS et al., 2017). Como também, pelo retorno de biogeoquímicos elementos aos seus respectivos ciclos, e a redução dos custos com fertilizantes industrializados, que geralmente são importados (BERTONCINI, 2014).

Por isso, o objetivo do presente estudo foi realizar uma revisão integrativa da literatura a fim de compreender a adubação do pimentão (Capsicum annuum) com a manipueira e seus efeitos.

\section{Material e métodos}

Foi feito um levantamento da literatura em janeiro de 202I, nas bases de dados Periódicos 
CAPES e Google Scholar. Os descritores utilizados foram os seguintes: 'Adubação" AND “Manipueira” AND 'Pimentão" e, em inglês, 'Fertilizing” AND 'Manipueira" AND 'Bell pepper" em ambas as bases de dados. Foram selecionados 03 artigos sendo incluídos segundo os critérios de elegibilidade conforme a Figura I. Os critérios de inclusão foram: artigos nos idiomas inglês e português, nos últimos cinco anos, envolven do Adubação do pimentão (Capsicum annuum) com a manipueira e seus efeitos. Os critérios de exclusão foram artigos de revisão de literatura.

\section{RESULTADOS}

Os resultados do presente estudo encontram-se na Tabela.

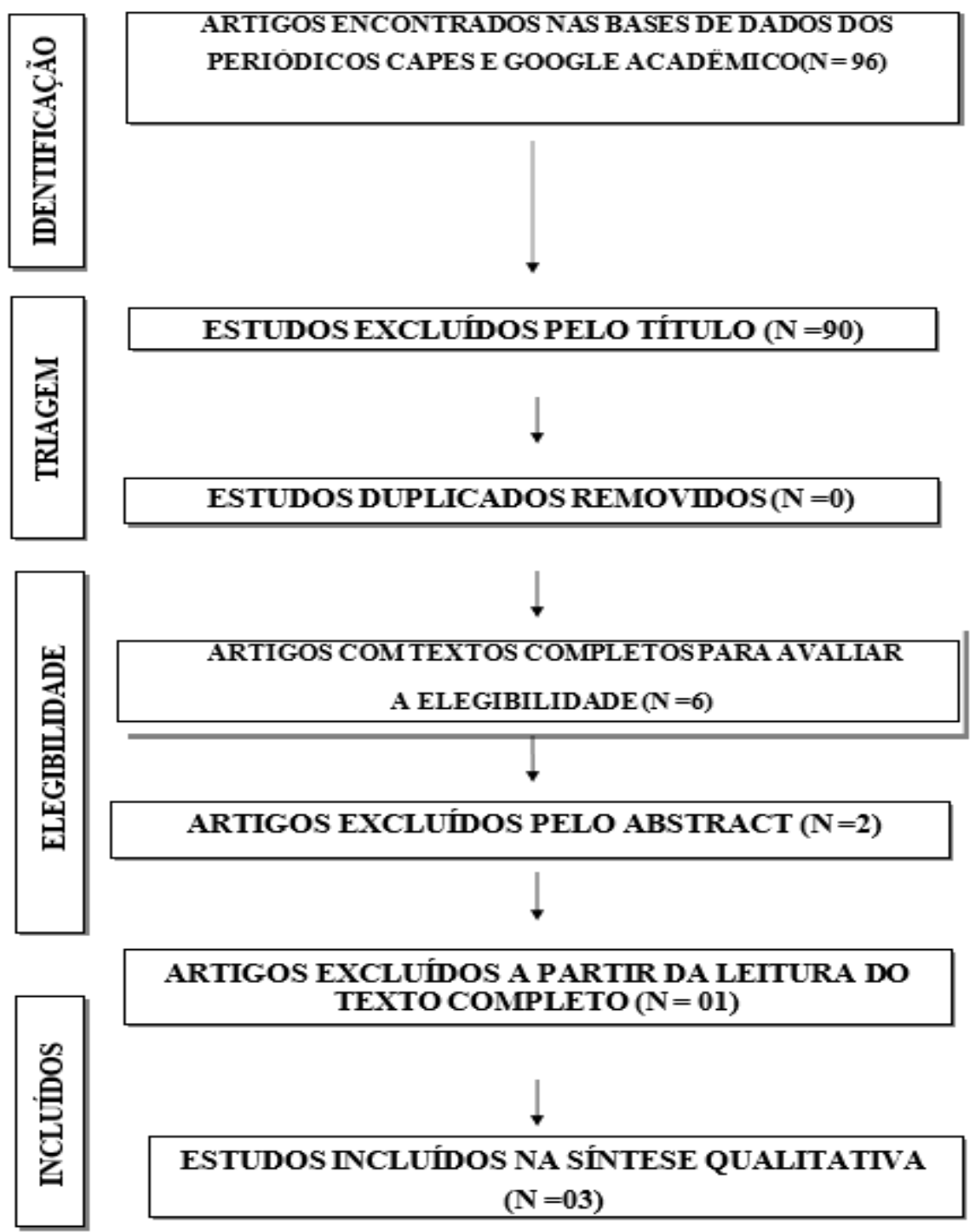


Tabelar - Demonstrativo dos artigos que integram a Revisão Integrativa

N Data

Título

Autores

Periódico

Objetivos

$\begin{array}{ll}\text { Brazilian } & \text { Discutir as principais características residuária } \\ \text { Journal of } & \text { destinada à irrigação por meio de levantamento de }\end{array}$

Irrigação no

Brasil: uma

Fernanda Lamede

Ferreirade Jesus;

abordagem

química,

física $e$

microbiológic

Otávio Neto

Vinicius Talamini

Junior; Tamara

Maria Gomes;

Fabrício Rossi e

Rodrigo Máximo

Sánchez román

Quality of

Yellow Bell

Pepper Fruits

Cultivated in

Fertilized

Soil with

Yellow

Water and

Cassava

Wastew ater
J. G. Ramos, M.

T. C. C. do

Nascimento,

R.F.B.Guimarães

M. de O.Pereirar

Journal of

cience

Avaliar a produção de frutos do híbrido Satrapo.

pimentão, sob fertilização com água amarela e esgoto

de mandioca

V. E. Borges N. C

de Araújo \& J. S.

dos Santos
AgriculturaS
Irrigation informações disponíveis na literatura específica.

Drainage com águas residuárias, ratifica a importância de se adotar uma política de reuso ainda mais específica no que diz respeito à utilização de águas residuárias em diversas atividades agrícolas, principalmente pela irrigação.
Houve diferenças significativas nas variáveis analisadas devido aos tratamentos aplicados. O tratamento correspondente a 2x Mandioca forneceu os melhores resultados para comprimento, diâmetro, espessura do mesocarpo, fitomassa fresca e seca dos frutos do pimentão. Pelo contrário, 2x Urina Humana foi o tratamento que forneceu osmenores valores para essas variáveis e follodę o maior número de lobos. 


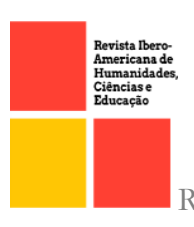

Revista Ibero-Americana de Humanidades, Ciências e Educação- REASE $\quad{ }_{\text {open }}^{\text {○access }}$

\begin{tabular}{llll}
\hline \multirow{3}{*}{2017} & Uso de & André Suêldo & XVI \\
& manipueir a & Tavares de Lima; & Encontro \\
& na adubação & Ellen Carine & de \\
& do pimentãonal & Neves Valente & Agroecolog \\
& & & ia do \\
& & & Nordeste
\end{tabular}

Avaliar o efeito da manipueira como fertilizante

potássico na adubação do pimentão. O

experimento foi conduzido em condições de

campo em delineamento em blocos casualizados

com quatro repetições. Foram testadas cinco dose

de manipueira $(0 ; 20 ; 40 ; 60 ; 80 \mathrm{~mL})$ os parâmetros

avaliados foram número de fruto, comprimento e

diâmetro de frutos.
A dose $20 \mathrm{~mL}$ promoveu o melhor resultado para comprimento e diâmetro de frutos.

Doses superiores a $20 \mathrm{~mL}$ reduziram o número, comprimento e diâmetro de frutos de pimentão 


\section{DISCUSSÃO}

O objetivo do presente estudo foi avaliar o desenvolvimento, qualidade microbiológica do fruto (pimentão) e possíveis contaminação do solo a partir da adubação com a manipueira.

Porquanto, a aplicação de adubos e corretivos na cultura do pimentão é uma prática agrícola onerosa que representa, em média, $23,4 \%$ do custo de produção (SANTOS et al., 2010).

Assim, o pimentão é bastante exigente no que diz respeito às características química e física do meio de cultivo, respondendo muito bem à adubação orgânica (SANTOS et al., 2010).

Um exemplo disso é a adubação orgânica com a manipueira conhecida também como tucupi que é um dos resíduos gerados no processamento da mandioca (LIMA e VALENTE, 2017).

Mas, o consumo de produtos agrícolas irrigados com água residuária como a manipueira é uma prática comum para mais de ıo\% da população mundial (ROSSI et al., 2020).

Porém, no Brasil o reuso dessa água ainda não possui um arcabouço legislativo que assegure a sua aplicação (ROSSI et al., 2020). É utilizada o CONAMA 357 de 17 de março de 2005 para à irrigação de hortaliças.

Nesse sentido, os parâmetros de qualidade de água são geridos pela Resolução no 357 do Conselho Nacional do Meio-Ambiente - CONAMA, de I7 de março de 2005 (ROSSI et al., 2020).

Porquanto, coloca a classificação de águas e os teores máximos permitidos de substâncias químicas que apresentam riscos potenciais ao ambiente, além de valores relativos a parâmetros físico, químicos e biológicos (ROSSI et al., 2020).

Nesse sentido, a metodologia da Avaliação Quantitativa do Risco Microbiológico (AQRM) poderia ser incluída na legislação brasileira (ROSSI et 
al., 2020).

Visto, que tem sido utilizada ao redor do mundo por organizações e agências regulatórias como a USEPA (United States Environmental Protection Agency), a FAO (Food and Agriculture Organization of United Nations) e a OMS (Organização Mundial da Saúde) (ROSSI et al., 2020).

Como também, para estabelecer políticas que visem à melhoria da qualidade da água, a segurança do alimento e, por conseguinte a promoção da saúde humana e para avaliar a eficiência dos programas e ações de intervenção realizadas (ROSSI et al., 2020).

Além disso, a qualidade microbiológica dos indicadores que geralmente são utilizados para verificar a qualidade da água incluem os coliformes totais e coliformes termotolerantes, os quais indicam possíveis contaminação da água por diferentes patógenos (ROSSI et al., 2020).

E, no que diz respeito à irrigação, existe a possibilidade de que a água apresente alto potencial patogênico para as culturas, a depender da carga microbiológica presente, visto que são conduzidas até o campo sem qualquer tratamento prévio (ROSSI et al., 2020).

Por exemplo, a Resolução CONAMA nº 357/2005, estabelece um limite de coliformes termotolerantes de $200 \mathrm{UFC} / \mathrm{I} 00 \mathrm{~mL}$ para água usada na irrigação de vegetais (ROSSI et al., 2020).

Porém, a contaminação fecal apresenta alta variabilidade, podendo partir de valores não detectáveis a $1^{6}-\mathrm{IO}^{7}$ UFC roo $\mathrm{mL}^{-1}$ de água, sendo usualmente estimada pelo nível populacional de coliformes termotolerantes (ROSSI et al., 2020).

No entanto, acima deste padrão pode gerar um conjunto de efeitos indesejáveis não só para as culturas (ROSSI et al., 2020).

Mas também, como veículo transmissor de doenças à população pela ingestão 
dos alimentos produzidos e pelo contato direto, no momento da operação dos sistemas de irrigação, assim como pela dispersão de aerossóis (ROSSI et al., 2020).

A saber, a qualidade microbiana da água usada na irrigação é de grande importância visto que a baixa qualidade da água, neste aspecto, pode favorecer a introdução de microrganismos patogênicos em produtos durante a pré e póscolheita (ROSSI et al., 2020).

Portanto, para avaliação microbiológica, na literatura é possível encontrar estudos que utilizaram a AQRM como metodologia para determinar o risco de contaminação por meio de experiências com o aproveitamento de águas residuárias, principalmente na irrigação (ROSSI et al., 2020).

A saber, os principais microrganismos representativos escolhidos nas análises de risco a saúde são geralmente os gastroenteríticos ou aqueles patógenos oportunistas periféricos (ROSSI et al., 2020).

Por exemplo, para a maioria deles a determinação é direta, porém para o Rotavirus, sua quantificação é estimada com base numa relação feita com Escherichia coli (ROSSI et al., 2020).

No entanto, no Brasil há uma escassez de trabalhos publicados em periódicos científicos que utilizem a $A Q R M$ no uso de águas residuárias na irrigação (ROSSI et al., 2020).

Entretanto, na literatura é possível encontrar o trabalho de Bastos et al., (2008), que usou esta metodologia em um experimento no sudeste brasileiro com culturas hortícolas irrigadas com efluentes de lagoa de estabilização (ROSSI et al., 2020).

Além disso, foram utilizados cenários com base em dados de campo e nas estatísticas oficiais de consumo de vegetais no Brasil (ROSSI et al., 2020).

Contudo, com os dados acima os valores encontrados pelos autores foram similares aos de Mara et al., (2007), trazendo novas evidências para a atualização 
das diretrizes da OMS (ROSSI et al., 2020).

Nesse sentido, Bastos et al., (2008) concluiu que a irrigação com efluentes que cumprem as diretrizes da OMS para irrigação irrestrita deve resultar em produtos com qualidade microbiológica aceitável para consumo (ROSSI et al., 2020).

Porém, águas residuárias utilizadas na irrigação de culturas podem conter contaminantes químicos potencialmente indesejáveis, como metais pesados e compostos orgânicos clorados (ROSSI et al., 2020).

Bem como, estes contaminantes podem ter efeitos adversos no solo, nas plantas e nas águas subterrâneas, se estiverem presentes em concentrações elevadas (ROSSI et al., 2020).

Mas, a magnitude dos seus impactos negativos depende da sua concentração, solubilidade e toxicidade (ROSSI et al., 2020).

Bem como, a frequência de aplicação das águas residuárias, das propriedades e condições intrínsecas ao solo, da vulnerabilidade do aquífero, das condições climáticas, do nível tecnológico e estado socioeconômico dos agricultores (ROSSI et al., 2020).

Como também, os contaminantes orgânicos transportados pelas águas residuárias, tais como compostos fenólicos, surfactantes, hidrocarbonetos aromáticos policíclicos (HAP), bifenilas policloradas e produtos farmacêuticos podem acumular-se nos solos devido à irrigação por longo prazo (ROSSI et al., $2020)$.

Portanto, estes compostos podem aumentar a toxicidade do solo e representar um potencial risco ecológico ao ecossistema do solo (ROSSI et al., 2020).

Sendo assim, a produtividade agrícola pode ser afetada negativamente pela absorção de metais pesados pelas plantas. No organismo humano, os metais pesados tem efeito e concentrações cumulativas e podem ocasionar doenças (ROSSI et al., 2020). 
Além disso, o potencial fitotoxicidade e consequentes efeitos no crescimento e / ou contaminação das plantas, os metais também podem perturbar as comunidades microbianas autóctonas (por exemplo, redução da biomassa microbiana ou alteração da estrutura da comunidade (ROSSI et al., 2020).

Bem como, os metais acumulados podem interagir sinergicamente com outros contaminantes, como antibióticos, acentuando seus efeitos potenciais (ROSSI et al., 2020).

Portanto, é fundamental a busca por sistema alternativo de produção que minimizem esses impactos (RAMOS et al., 2017). Um exemplo disso é a utilização da manipueira.

Nesse sentido, a avaliação do efeito de diferentes doses de manipueira como fertilizante potássico na adubação do pimentão foi referente aos parâmetros de rendimento de frutos por planta: diâmetro e comprimento (LIMA e VALENTE, 2017).

No entanto, o experimento foi conduzido em condição de campo com solo com características químicas: $\mathrm{pH}=4,3 ; \mathrm{M} . \mathrm{O}=9 \mathrm{~g} \mathrm{dm}^{3-1} ; \mathrm{P}=3 \mathrm{mg} \mathrm{dm}^{3-1} ; \mathrm{K}=0,6$; $\mathrm{Ca}=4 ; \mathrm{Mg}=2 ; \mathrm{H}+\mathrm{Al}=20 ; \mathrm{SB}=6,6 ; \mathrm{T}=26,6 \mathrm{mmol}_{\mathrm{c}} \mathrm{dm}^{3-\mathrm{I}} ; \mathrm{V} \%=25(\mathrm{LIMA} \mathrm{e}$ VALENTE, 2017).

Bem como, com delineamento experimental utilizado em blocos casualizados com cinco tratamentos e quatro blocos, totalizando 20 unidades experimentais (LIMA e VALENTE, 2017).

Além disso, os tratamentos constaram de $\mathrm{T}_{\mathrm{I}}=$ controle (sem manipueira); $\mathrm{T}_{2}$ $=20 \mathrm{~mL} ; \mathrm{T}_{3}=40 \mathrm{~mL} ; \mathrm{T}_{4}=60 \mathrm{~mL} ; \mathrm{T}_{5}=80 \mathrm{~mL}$ de manipueira por planta (LIMA e VALENTE, 2017).

Porquanto, a manipueira foi aplicada semanalmente nas covas, com parcelas que constaram em 4 linhas de cultivo com 4 plantas por linha, além disso a área útil da parcela foi representada pelas quatro plantas centrais (LIMA e VALENTE, 2017). 
Assim, as mudas de pimentão foram produzidas em copos plásticos descartável com capacidade para $300 \mathrm{~mL}$, contendo substrato (terra vegetal e esterco na proporção 2:I) e transplantadas para as covas quando as plântulas apresentarem 4-5 folhas definitivas (LIMA e VALENTE, 2017).

E, as covas foram abertas com dimensões de $15 \times 15 \times 15 \mathrm{~cm}$ e foram submetidas à calagem de acordo com a análise do solo, com trinta dias antes do transplante das mudas. A adubação com $\mathrm{N}$ e $\mathrm{P}$ seguiu a recomendação para cultura do pimentão (LIMA e VALENTE, 2017).

Assim, o espaçamento de plantio foi I $\mathrm{m}$ entre linhas por $0,5 \mathrm{~m}$ entre plantas. A irrigação foi realizada com fitas gotejadoras com emissores espaçados de $0,5 \mathrm{~cm}$, em turno de regas três horas dias (LIMA e VALENTE, 2017).

\section{CONCLUSÃO}

O objetivo do presente estudo foi avaliar o desenvolvimento, qualidade microbiológica do fruto (pimentão) e possíveis contaminação do solo a partir da adubação com a manipueira.

Porquanto, a opinião dos professores é que a dose de $20 \mathrm{~mL}$ de manipueira promove melhores resultados para comprimento e diâmetros de frutos de pimentão. Doses maiores que $20 \mathrm{~mL}$ reduz número, comprimento e diâmetro de frutos de pimentão.

Nesse sentido, Bastos et al., (2008) concluiu que a irrigação com efluentes que cumprem as diretrizes da OMS para irrigação irrestrita deve resultar em produtos com qualidade microbiológica aceitável para consumo.

Além disso, o uso da manipueira embora apresente vantagens dentro da temática dos recursos hídricos e a produção agrícola, requer uma abordagem mais cautelosa, visto que a pesquisa e a legislação ainda são incipientes, tanto no Brasil, quanto em outros locais do mundo.

No entanto, este fato, ratifica a importância de se adotar uma política de reuso ainda mais específica no que diz respeito à utilização de águas residuárias em diversas atividades agrícolas, principalmente pela irrigação. 
Não só isso, mas a utilização de águas residuárias na fertiirigação de culturas agrícolas pode aumentar a produtividade e a qualidade dos produtos colhidos, reduzindo a poluição ambiental e a melhoria físicas, químicas e biológicas do solo (Matos, 2007).

Contudo, a perspectiva de avanço nas pesquisas com águas residuárias poderá fornecer informações que venham a contribuir para o aprimoramento da legislação específica no Brasil, afim de favorecer a segurança ao agricultor, ao ambiente e ao alimento, além de confiança ao consumidor.

\section{REFERÊNCIAS BIBLIOGRÁFICAS}

BASTOS, R. K. X.; BEVILACQUA, P. D.; SILVA, C. A. B.; SILVA, C. V. Wastew ater irrigation of salad crops: further evidence for the evaluation of the WHO guidelines. Water Science and Technology, Oxford, v. 57, n. 8, p. 1213-1219, 2008.

BERTONCINI, E. I. (2014). Tratamento, uso e impacto de resíduos urbanos e agroindustriais na agricultura. Pesquisa \& Tecnologia. greyw ater. Geneva: WHO, 2006

BRASIL. Ministério do Meio Ambiente. Conselho Nacional do Meio Ambiente. Resolução $n^{\circ} 357$, de 17 de março de 2005. Dispõe sobre a classificação dos corpos de água e diretrizes ambientais para o seu enquadramento, bem como estabelece as condições e padrões de lançamento de efluentes, e dá outras providências. Brasília, DF: Ministério do Meio Ambiente, 2005. Disponível em: http://www 2.mma.gov.br/port/conama/legiabre.cfm?codlegi=459. Acesso em: 22 out. 2017.

JESUS, F.L.F; SANTOS, O.N.A; JUNIOR, M.V.T; GOMES, T.M; ROSSI, F; ROMÁN, R.M.S. Águas residuárias para irrigação no Brasil: Uma abordagem química, física e microbiológica, Irriga, Botucatu, v. 25, n. 3, p. 562-589, julho-setembro, 2020. A.S.T.

MARA, D.; SLEIGH, P.; BLUMENTHAL, U.; CARR, R. Health risks in wastew ater irrigation: comparing estimates from quantitative microbial risk analyses and epidemiological studies. Journal of Water and Health, London, v. 5, n.I, p. 39-50, 2007. 
MATOS, A. T. Disposição de águas residuárias no solo. Viçosa, MG: AEAGRI, v. I40, 2007 .

RAMOS, J. G.; NASCIMENTO, M. T. C. C.; GUIMARÃES, R. F. B.; PEREIRA, M. de O.; BORGES, V. E.; ARAUJO, N.C.; SANTOS, J. S. Quality of Yellow Bell Pepper Fruits Cultivated in Fertilized Soil with Yellow Water and Cassava Wastewater, v. 9, n. Io, Setembro, 2017.

SANTOS, M. R. dos; SEDIYAMA, M. A. N.; SALGADO, L. T.; VIDIGAL, S. M.; REIGADO, F. R. Produção de mudas de pimentão em substratos à base de vermicomposto. Bioscience Journal 26: 572-578. Uberlândia/MG, 2010.

VALENTE, E.C.N; LIMA, A.S.T. Uso de manipueira na adubação do pimentão. XVI Encontro regional de agroecologia do nordeste, 2017.

UNITED STATES ENVIRONMENTAL PROTECTION AGENCY. Office of Water 820-Fi2-058: Recreational Water Quality Criteri 